\title{
Comorbidity and survival of Danish lung cancer patients from 2000-20I I: a population-based cohort study
}

This article was published in the following Dove Press journal:

Clinical Epidemiology

I November 2013

Number of times this article has been viewed

\author{
Thomas Deleuran ${ }^{1,2}$ \\ Reimar Wernich Thomsen' \\ Mette Nørgaard' \\ Jacob Bonde Jacobsen' \\ Torben Riis Rasmussen ${ }^{3}$ \\ Mette Søgaard' \\ 'Department of Clinical Epidemiology, \\ ${ }^{2}$ Department of Medicine $\mathrm{V}$, \\ Hepatology and Gastroenterology, \\ ${ }^{3}$ Department of Respiratory Medicine, \\ Aarhus University Hospital, Aarhus, \\ Denmark
}

Objective: To examine lung cancer survival and the impact of comorbidity in the Central Denmark Region from 2000 to 2011.

Methods: We performed a population-based cohort study of lung cancer patients diagnosed during four 3-year calendar periods (2000-2002, 2003-2005, 2006-2008, and 2009-2011) in the Central Denmark Region. The Danish National Registry of Patients was used to identify 9,369 incident lung cancer patients, and to obtain data on their Charlson comorbidity index score, categorized as no (score $=0$ ), medium ( calculated 1 - and 5-year survival in different calendar time periods overall, and by age, sex, and level of comorbidity, and used Cox regression to compute mortality rate ratios (MRR) for each level of comorbidity versus no comorbidity in different calendar time periods.

Results: Overall 1-year survival increased from 31\% in $2000-2002$ to $37 \%$ in $2009-2011$, while the 5-year survival increased from 10\% in 2000-2002 to predicted 13\% in 2009-2011 with the largest improvement observed for women and patients less than 80 years. The adjusted 1-year MRR in patients with high comorbidity compared with those without comorbidity was 1.23 (95\% confidence interval [CI]: 1.05-1.46) in 2000-2002 and 1.35 (95\% CI: $1.17-1.56$ ) in 2009-2011. The corresponding adjusted 5-year MRRs were 1.21 (95\% CI: 1.04-1.40) in 2000-2002 and 1.26 (95\% CI: 1.11-1.42) in 2009-2011.

Conclusion: Lung cancer patients' survival increased from 2000 to 2011 in the Central Denmark Region, most prominently for women under 80 years and patients with no, or medium level of comorbidity. Their prognosis remained nonetheless dismal with overall 5-year survival of $13 \%$, and comorbidity remained a negative prognostic factor.

Keywords: mortality, lung cancer, comorbidity, time-trends

\section{Introduction}

Lung cancer is one of the most frequent cancers and the leading cause of cancer-related mortality in Denmark and worldwide. ${ }^{1}$ On a global basis approximately 1.6 million people are afflicted by lung cancer annually ${ }^{1}$ and the 5 -year survival rate is less than $15 \%{ }^{2-4}$ Lung cancer is associated with high age and presence of comorbidity ${ }^{5}$ and, in Denmark, the median age at diagnosis is 69 years, with the prevalence of comorbidity in lung cancer patients at about $50 \% .{ }^{6}$ Smoking is a likely explanation to much of the association between comorbidity and lung cancer, ${ }^{7}$ as smoking causes the majority of lung cancer cases ${ }^{8}$ and is also associated with a range of comorbid conditions such as chronic obstructive pulmonary disease (COPD) ${ }^{9}$ and cardiovascular disease.

The prognosis for lung cancer patients depends on age, cancer stage, sex, and level of comorbidity. ${ }^{10-13}$ The impact of comorbidity on lung cancer survival has been
Correspondence: Thomas Deleuran Department of Clinical Epidemiology, Aarhus University Hospital,

Olof Palmes Allé 43-45, DK-8200,

Aarhus N, Denmark

Tel +45 87I 34797

Fax +4587167215

Email thomas.deleuran@dce.au.dk
(C) 2013 Deleuran et al, publisher and licensee Dove Medical Press Ltd. This is an Open Access article which permits unrestricted noncommercial use, provided the original work is properly cited. 
studied across different populations and cancer stages. . $^{2,5,11,14,15}$ These cohort studies found mortality hazard ratios (HRs) ranging from 1.3 to 1.5 in patients with comorbidity and suggested that the increased mortality was due to poorer outcome after surgery. ${ }^{2,15,16}$ However, other studies have claimed that comorbidity is of minor importance because of the dismal prognosis for lung cancer patients per se. ${ }^{17,18}$ It is also unclear whether the impact of comorbidity on lung cancer survival is a constant property or if the association has changed over time.

In Denmark, a number of nationwide clinical quality programs to improve cancer survival have been introduced since 2000. The National Cancer Plan which focuses on cancer prevention, early detection, and improved treatment was initiated in $2000^{19}$ and updated twice, in 2005 and 2011. The National integrated cancer pathways, allowing fast, structured, and uniform work-up and initiation of treatment for all patients with suspected cancer in the public health care system was implemented in $2009 .{ }^{20}$ Moreover, the proportion of patients who received adjuvant chemotherapy after resections or platinum-based chemotherapy for stage III and IV lung cancer increased from $10 \%$ in 2003 to $31 \%$ in $2011 .^{21}$ Thus, time-trends in lung cancer survival during this period are highly relevant.

In this context, we examined overall survival in Danish lung cancer patients from 2000 through 2011 and stratified the analysis by age, sex, and level of comorbidity.

\section{Material and methods Study population}

We conducted this population-based cohort study in the Central Denmark Region with a population of approximately 1.3 million citizens. The Danish National Health service provides universal, tax-supported health care, guaranteeing unconstrained access to general practitioners and hospitals. Accurate and unambiguous individual-level linkage of all registries is enabled by means of the unique personal identifier issued by the Danish Civil Registration System to all Danish citizens at birth or emigration. This registry also records the exact date of death or emigration for all Danish citizens and is continuously updated.

\section{Identification of patients with lung cancer}

The Danish National Registry of Patients (DNRP) contains information on all discharges from non-psychiatric hospitals in Denmark since 1977, and from emergency room and outpatient visits at hospitals since 1995. Each hospital discharge or outpatient visit is recorded in the registry with one primary diagnosis and one or more secondary diagnoses classified according to the International Classification of Diseases 10th Revision (ICD-10). Using the DNRP, we identified all patients with a diagnosis of lung cancer (ICD-10 codes: DC34) from January 1, 2000 to December 31, 2011.

\section{Comorbidity at diagnosis}

We computed Charlson comorbidity index (CCI $)^{22}$ scores for each lung cancer patient based on DNRP hospitalization records of outpatient visits and inpatient hospitalizations within 10 years preceding the date of cancer diagnosis. The CCI has been adapted and validated for use with hospital discharge data for the prediction of short- and long-term survival. ${ }^{23}$ The following disease categories are included: liver diseases, myocardial infarction, congestive heart failure, peripheral vascular disease, chronic pulmonary disease, cerebrovascular disease, hemiplegia, dementia, connective tissue disease, peptic ulcer disease, type 1 and 2 diabetes, renal disease, hematological and solid cancer, and HIV/ AIDS. Lung cancer diagnoses were excluded when we computed the CCI score. Cancer diagnoses within 60 days before the lung cancer diagnosis were excluded from the CCI score calculations, to eliminate possible nonspecific cancer diagnoses assigned during the diagnostic work-up for lung cancer. We categorized comorbidities as no (CCI score $=0$ ), medium $($ CCI score $=1-2)$, or high $($ CCI score $\geq 3$ ).

\section{Statistical analysis and follow-up}

We computed the prevalence of comorbidity in study patients during four, 3-year study periods (2000-2002, 2003-2005, 2006-2008, and 2009-2011). For each comorbidity category, we constructed Kaplan-Meier survival curves for the different study periods. Follow-up was based on date of death or December 31, 2011, whichever occurred first. Next, we used Cox proportional hazards regression to compute 1- and 5-year crude, age, and sex-adjusted HRs, as a measure of relative mortality (mortality rate ratios [MRR]) to assess the association of comorbidity with relative survival using the Charlson score of 0 as the reference category in each time period, and to compare the survival for each study period to the survival in 2000-2002; additionally, we adjusted for comorbidity in the latter analysis. The 5-year survival of patients diagnosed later than 2006 was estimated using a hybrid analysis in which survival was estimated using the survival experience of patients in the previous periods. ${ }^{24}$ Estimated values are denoted with a dagger $(\dagger)$. The proportional hazards assumption was assessed graphically and found to be appropriate. 
All analyses were performed using SAS version 9.2 (SAS Institute Inc, Cary, NC, USA) and results are presented with corresponding 95\% confidence intervals (CI). The Danish Data Protection Agency approved the study (record number 2009-41-3866).

\section{Results}

We identified 9,369 lung cancer patients (54\% males) in the Central Denmark Region, from 2000 to 2011 . Of these, 4,716 patients (50\%) had no hospital-recorded comorbidity; 3,390 (36\%) had medium level comorbidity; and 1,263 (14\%) had high level comorbidity. Median age at diagnosis increased from 69 years in 2000-2002 to 71 years in 2009-2011. Patients with comorbidity were older than those without and there was a slight increase in the prevalence of patients with a high level comorbidity from $11 \%$ in $2000-2002$ to $15 \%$ in 2009-2011, whereas the prevalence of medium comorbidity remained stable (data not shown).

Overall 1-year survival increased from 31\% (95\% CI: $29 \%-33 \%$ ) in $2000-2002$ to $37 \%$ (95\% CI: $35 \%-39 \%$ ) in 2009-2011 with a corresponding age, sex, and comorbidity adjusted MRR of $0.80(0.74-0.86)$ in 2009-2011 versus 2000-2002 (Table 1 and Figure 1). Overall 5-year survival increased from $10 \%$ (95\% CI: $9 \%-12 \%$ ) in $2000-2002$ to $13 \%$ (95\% CI: $12 \%-15 \%)^{\dagger}$ in 2009-2011, with a corresponding adjusted MRR of 0.83 (95\% CI: $0.78-0.88)^{\dagger}$ when comparing 2009-2011 with 2000-2002 (Table 1 and Figure 1).

There was a moderate increase in 1-year survival of about 6\% among men in all age groups from 2002 to 2011. The increase in 1-year survival among women was most prominent in women aged $70-79$ years (from $29 \%$ to $41 \%$ ), whereas it was moderate in women aged 15-69 years (from
$39 \%$ to $48 \%$ ), and unaltered among women above 80 years. The 5-year survival among men of all age groups remained unchanged over time; around 14\% for men aged 15-69 years and less than $5 \%$ for men above 80 years, except for a moderate increase in those aged $70-79$ years from $8 \%$ to $12 \%$. In contrast, the 5-year survival among women increased from $14 \%$ to $21 \%$ in women aged $15-69$ years, and from $7 \%$ to $14 \%$ in those aged $70-79$ years, while women above 80 years saw no improvement (Table 2).

Across all calendar time periods, a high level of comorbidity was a negative predictor of 1-year and 5-year cancer survival. The 1-year survival for patients with no comorbidity increased from 33\% (95\% CI: 31\%-36\%) in 2000-2002 to $41 \%$ (95\% CI: $38 \%-44 \%$ ) in 2009-2011, while the 1-year survival for patients with medium level comorbidity increased from $29 \%$ (95\% CI: $26 \%-32 \%$ ) to $37 \%$ (95\% CI: $33 \%-40 \%$ ). In comparison, the increase in 1-year survival for patients with a high level of comorbidity was less prominent - from $25 \%$ (95\% CI: $20 \%-31 \%$ ) to $28 \%$ (95\% CI: $23 \%-33 \%$ ). The corresponding 1-year MRR adjusted for age and sex in patients with a high level of comorbidity versus no comorbidity was 1.23 (95\% CI: 1.05-1.46) in 2000-2002 and 1.35 (95\% CI: 1.17-1.56) in 2009-2011 (Table 3, Figures 2-4). The 5-year survival for patients with no comorbidity increased from $12 \%$ (95\% CI: $10 \%-14 \%$ ) in $2000-2002$ to $15 \%$ (95\% CI: $13 \%-18 \%)^{\dagger}$ in 2009-2011 (Table 3, Figure 2) and the 5-year survival for patients with medium level comorbidity increased from $9 \%(95 \%$ CI: $7 \%-11 \%)$ in $2000-2002$ to $13 \%(11 \%$ $15 \%)^{\dagger}$ in 2009-2011 (Table 3, Figure 3), while the 5-year survival for patients with high level comorbidity remained stable around 7\% (Table 3, Figure 4). The corresponding 5-year MRRs adjusted for age and sex in patients with a high level

Table I Overall I- and 5-year survival and mortality rate ratios (MRRs) after lung cancer cancer diagnosis according to study periods in the Central Denmark Region 2000-20II

\begin{tabular}{|c|c|c|c|c|}
\hline \multirow[t]{2}{*}{ Lung cancer } & \multicolumn{4}{|c|}{ Year of diagnosis } \\
\hline & $2000-2002$ & 2003-2005 & $2006-2008$ & $2009-2011$ \\
\hline Number of patients & 2,169 & 2,188 & 2,464 & 2,548 \\
\hline Median age & 69 years & 69 years & 70 years & 71 years \\
\hline \multicolumn{5}{|l|}{ I year } \\
\hline Survival & $31 \%(29 \%-33 \%)$ & $34 \%(32 \%-36 \%)$ & $34 \%(32 \%-36 \%)$ & $37 \%(35 \%-39 \%)$ \\
\hline MRR & I (reference) & $0.93(0.87-1.00)$ & $0.92(0.86-0.99)$ & $0.84(0.78-0.90)$ \\
\hline Adjusted MRR* & I (reference) & $0.92(0.86-0.99)$ & $0.89(0.83-0.96)$ & $0.80(0.75-0.86)$ \\
\hline Adjusted MRR** & I (reference) & $0.92(0.85-0.99)$ & $0.89(0.83-0.95)$ & $0.80(0.74-0.86)$ \\
\hline \multicolumn{5}{|l|}{5 years } \\
\hline Survival & $10 \%(9 \%-12 \%)$ & $10 \%(9 \%-12 \%)$ & $12 \%(11 \%-13 \%)^{\dagger}$ & $13 \%(12 \%-15 \%)^{\dagger}$ \\
\hline MRR & I (reference) & $0.97(0.91-1.03)$ & $0.93(0.87-0.99)^{\dagger}$ & $0.87(0.82-0.93)^{\dagger}$ \\
\hline Adjusted MRR* & I (reference) & $0.96(0.90-1.02)$ & $0.90(0.85-0.96)^{\dagger}$ & $0.83(0.78-0.89)^{\dagger}$ \\
\hline Adjusted MRR** & I (reference) & $0.95(0.90-1.02)$ & $0.90(0.84-0.96)^{\dagger}$ & $0.83(0.78-0.88)^{\dagger}$ \\
\hline
\end{tabular}

Note: *Adjusted for differences in age and sex; ${ }^{*}$ adjusted for differences in age, sex, and comorbidity; ${ }^{\dagger}$ predicted values. 


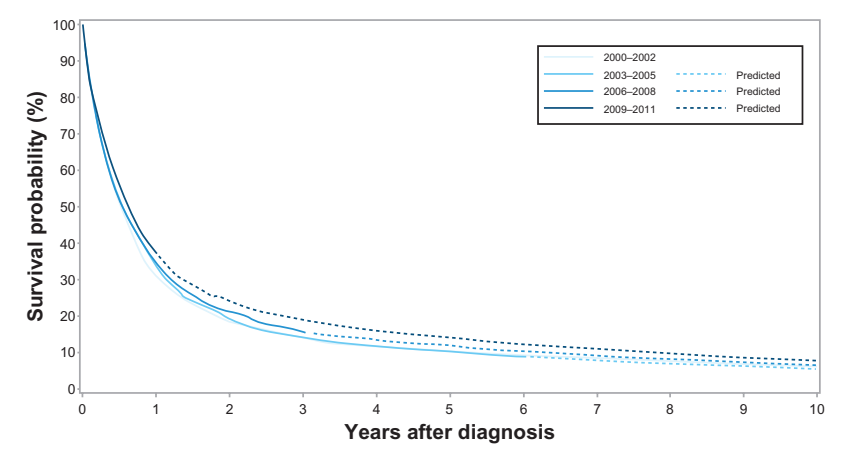

Figure I Kaplan-Meier curves for lung cancer patients in the Central Denmark Region for four study periods.

of comorbidity versus no comorbidity remained essentially unchanged at 1.21 (95\% CI: 1.04-1.40) in 2000-2002 and 1.26 (95\% CI: 1.11-1.42) $)^{\dagger}$ in 2009-2011.

\section{Discussion}

This population-based cohort study revealed an improvement in overall survival of lung cancer patients diagnosed in the Central Denmark Region from 2000 through 2011. The improvement was most prominent in women, patients below 80 years, and in patients with no or medium level comorbidity. Nonetheless, the long-term prognosis of lung cancer remained poor with an overall 5-year survival of about $13 \%$. And, comorbidity remained a negative predictor of survival with adjusted mortality rates elevated 1.3-fold when comparing patients with high comorbidity level with patients without comorbidity in 2009-2011.

Our findings of an adverse prognostic impact of comorbidity after adjustment for age and sex are in agreement with several previous studies. ${ }^{10,11,25}$ But they disagree with the findings in a Norwegian study on the survival and risk of side effects among 402 stage IIIB/IV lung cancer patients using data from a Phase III trial of two different platinumbased chemotherapy regimes. ${ }^{17}$ In that study, comorbidity had no effect on survival (HR for severe versus no comorbidity was 0.98) (95\% CI: 0.66-1.44). Patients with World Health Organization performance status $<2$ were however excluded from this study, and therefore most likely also the patients with the most severe comorbidity and hence worst prognosis, which may explain the lack of association between survival and level of comorbidity.

There are several plausible explanations for the improvement in the overall survival of lung cancer patients between 2000 and 2011. Both the introduction of the National Cancer Plan and the National Integrated Cancer Pathways in Denmark along with more aggressive therapy, especially the introduction of adjuvant chemotherapy ${ }^{4}$ and platinum-based

Table $2 \mathrm{I}$ - and 5-years survival by age, sex and year of diagnosis

\begin{tabular}{|c|c|c|c|c|}
\hline & $2000-2002$ & 2003-2005 & 2006-2008 & $2009-2011$ \\
\hline \multicolumn{5}{|l|}{ Men } \\
\hline \multicolumn{5}{|l|}{$15-69$ years } \\
\hline Number of patients & 617 & 590 & 617 & 607 \\
\hline I-year survival & $35 \%(31 \%-39 \%)$ & $37 \%(33 \%-41 \%)$ & $36 \%(32 \%-39 \%)$ & $41 \%(37 \%-45 \%)$ \\
\hline 5-year survival & $14 \%(11 \%-17 \%)$ & $10 \%(8 \%-13 \%)$ & $12 \%(10 \%-15 \%)^{\dagger}$ & $14 \%(1 \mid \%-17 \%)^{\dagger}$ \\
\hline \multicolumn{5}{|l|}{$70-79$ years } \\
\hline Number of patients & 427 & 447 & 461 & 477 \\
\hline I-year survival & $29 \%(24 \%-33 \%)$ & $27 \%(23 \%-31 \%)$ & $32 \%(27 \%-36 \%)$ & $34 \%(29 \%-39 \%)$ \\
\hline 5-year survival & $8 \%(5 \%-11 \%)$ & $7 \%(5 \%-10 \%)$ & $11 \%(8 \%-14 \%)^{\dagger}$ & $12 \%(9 \%-15 \%)^{\dagger}$ \\
\hline \multicolumn{5}{|l|}{$80+$ years } \\
\hline Number of patients & 154 & 168 & 219 & 230 \\
\hline I-year survival & $15 \%(10 \%-21 \%)$ & $18 \%(13 \%-25 \%)$ & $20 \%(15 \%-26 \%)$ & $22 \%(16 \%-28 \%)$ \\
\hline 5-year survival & $2 \%(1 \%-5 \%)$ & $3 \%(1 \%-6 \%)$ & $4 \%(2 \%-7 \%)^{\dagger}$ & $5 \%(3 \%-9 \%)^{\dagger}$ \\
\hline \multicolumn{5}{|l|}{ Women } \\
\hline \multicolumn{5}{|l|}{$15-69$ years } \\
\hline Number of patients & 545 & 541 & 583 & 593 \\
\hline I-year survival & $39 \%(35 \%-43 \%)$ & $46 \%(41 \%-50 \%)$ & $45 \%(41 \%-49 \%)$ & $48 \%(44 \%-53 \%)$ \\
\hline 5-year survival & $14 \%(12 \%-18 \%)$ & $16 \%(13 \%-19 \%)$ & $18 \%(15 \%-22 \%)^{\dagger}$ & $21 \%(18 \%-24 \%)^{\dagger}$ \\
\hline \multicolumn{5}{|l|}{ 70-79 years } \\
\hline Number of patients & 312 & 334 & 407 & 408 \\
\hline I-year survival & $25 \%(21 \%-30 \%)$ & $29 \%(25 \%-34 \%)$ & $35 \%(30 \%-40 \%)$ & $41 \%(36 \%-46 \%)$ \\
\hline 5-year survival & $7 \%(4 \%-10 \%)$ & $10 \%(7 \%-13 \%)$ & $12 \%(9 \%-15 \%)^{\dagger}$ & $14 \%(1 \mid \%-18 \%)^{\dagger}$ \\
\hline \multicolumn{5}{|l|}{$80+$ years } \\
\hline Number of patients & 114 & 108 & 177 & 233 \\
\hline I-year survival & $18 \%(12 \%-26 \%)$ & $21 \%(14 \%-29 \%)$ & $17 \%(12 \%-23 \%)$ & $17 \%(12 \%-23 \%)$ \\
\hline 5-year survival & $3 \%(1 \%-7 \%)$ & $7 \%(3 \%-13 \%)$ & $4 \%(2 \%-8 \%)^{\dagger}$ & $3 \%(1 \%-6 \%)^{\dagger}$ \\
\hline
\end{tabular}

Note: ${ }^{\dagger}$, estimated values. 
Table $3 \mathrm{I}$ - and 5-year survival and mortality rate ratios (MRRs) after lung cancer diagnosis by level of comorbidity and study period in the Central Denmark Region 2000-20I I

\begin{tabular}{|c|c|c|c|}
\hline Charlson score & 0 & I-2 & $3+$ \\
\hline \multicolumn{4}{|l|}{$2000-2002$} \\
\hline Number of patients & 1143 & 792 & 234 \\
\hline Median age & 67 years & 71 years & 71 years \\
\hline \multicolumn{4}{|l|}{ I-year } \\
\hline Survival & $33 \%(31 \%-36 \%)$ & $29 \%(26 \%-32 \%)$ & $25 \%(20 \%-31 \%)$ \\
\hline MRR & I (reference) & $1.16(1.04-1.30)$ & $1.31(1.11-1.54)$ \\
\hline Adjusted MRR* & I (reference) & $1.10(0.98-1.23)$ & $1.23(1.05-1.46)$ \\
\hline \multicolumn{4}{|l|}{ 5-year } \\
\hline Survival & $12 \%(10 \%-14 \%)$ & $9 \%(7 \%-11 \%)$ & $6 \%(4 \%-10 \%)$ \\
\hline MRR & I (reference) & $1.14(1.04-1.26)$ & $1.28(1.11-1.49)$ \\
\hline Adjusted MRR* & I (reference) & $1.09(0.99-1.20)$ & $1.21(1.04-1.40)$ \\
\hline \multicolumn{4}{|l|}{$2003-2005$} \\
\hline Number of patients & 1096 & 780 & 312 \\
\hline Median age & 67 years & 71 years & 72 years \\
\hline \multicolumn{4}{|l|}{ I-year } \\
\hline Survival & $35 \%(32 \%-38 \%)$ & $34 \%(31 \%-38 \%)$ & $28 \%(23 \%-33 \%)$ \\
\hline MRR & I (reference) & $1.06(0.94-1.18)$ & $1.22(1.05-1.42)$ \\
\hline Adjusted MRR* & I (reference) & $0.97(0.87-1.09)$ & $1.12(0.96-1.30)$ \\
\hline \multicolumn{4}{|l|}{ 5-year } \\
\hline Survival & $12 \%(10 \%-14 \%)$ & $9 \%(7 \%-11 \%)$ & $8 \%(5 \%-11 \%)$ \\
\hline MRR & I (reference) & $1.06(0.96-1.17)$ & $1.17(1.02-1.33)$ \\
\hline Adjusted MRR* & I (reference) & $0.99(0.90-1.10)$ & $1.10(0.96-1.26)$ \\
\hline \multicolumn{4}{|l|}{ 2006-2008 } \\
\hline Number of patients & 1240 & 893 & 331 \\
\hline Median age & 68 years & 72 years & 73 years \\
\hline \multicolumn{4}{|l|}{ I-year } \\
\hline Survival & $36 \%(33 \%-39 \%)$ & $33 \%(30 \%-36 \%)$ & $31 \%(26 \%-36 \%)$ \\
\hline MRR & I (reference) & $1.10(0.99-1.22)$ & $1.21(1.04-1.40)$ \\
\hline Adjusted MRR* & I (reference) & $1.03(0.93-1.15)$ & I.I5 (0.99-I.33) \\
\hline \multicolumn{4}{|l|}{ 5-year } \\
\hline Survival & $14 \%(12 \%-16 \%)^{\dagger}$ & $12 \%(10 \%-14 \%)^{\dagger}$ & $6 \%(4 \%-9 \%)^{\dagger}$ \\
\hline MRR & I (reference) & $1.08(0.98-1.18)^{\dagger}$ & $1.27(1.12-1.44)^{\dagger}$ \\
\hline Adjusted MRR* & I (reference) & $1.02(0.93-1.12)^{\dagger}$ & $1.22(1.07-1.38)^{\dagger}$ \\
\hline \multicolumn{4}{|l|}{ 2009-20II } \\
\hline Number of patients & 1237 & 925 & 386 \\
\hline Median age & 68 years & 73 years & 75 years \\
\hline \multicolumn{4}{|l|}{ I-year } \\
\hline Survival & $41 \%(38 \%-44 \%)$ & $37 \%(33 \%-40 \%)$ & $28 \%(23 \%-33 \%)$ \\
\hline MRR & I (reference) & $1.15(1.03-1.29)$ & $1.55(1.35-1.79)$ \\
\hline Adjusted MRR* & I (reference) & $1.08(0.96-1.21)$ & $1.35(1.17-1.56)$ \\
\hline \multicolumn{4}{|l|}{ 5-year } \\
\hline Survival & $15 \%(13 \%-18 \%)^{\dagger}$ & $13 \%(11 \%-15 \%)^{\dagger}$ & $7 \%(5 \%-11 \%)^{\dagger}$ \\
\hline MRR & I (reference) & $1.11(1.01-1.22)^{\dagger}$ & $1.40(1.24-1.58)^{\dagger}$ \\
\hline Adjusted MRR* & I (reference) & $1.04(0.95-1.15)^{\dagger}$ & $1.26(1.11-1.42)^{\dagger}$ \\
\hline
\end{tabular}

Notes: *Adjusted for differences in age and sex; ${ }^{\dagger}$, estimated values.

chemotherapy for stage III and IV lung cancer ${ }^{26}$ in this period, are likely to have contributed. Indeed, the proportion of patients who received chemotherapy for lung cancer in Denmark increased from $10 \%$ to $31 \%$ in this period. ${ }^{21}$ Most importantly, the unequal improvements in survival between strata of age, sex, and comorbidity in our study suggest that the improved overall survival is caused by factors other than just a potential lead time bias introduced by the faster work-up, and thus earlier diagnosis incorporated in the National integrated cancer pathways. It is however unclear, why patients with a high comorbidity level seem to be less affected by this survival improvement compared to patients with low, or no comorbidity. The design of our study prevents us from investigating this further, though we may hypothesize some mechanisms. Patients with comorbidity have a higher risk of dying from other causes than patients without comorbidity, and changes 


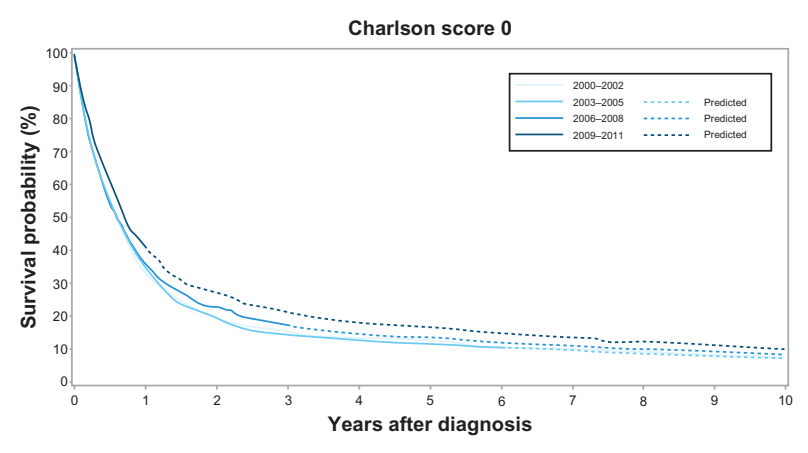

Figure 2 Kaplan-Meier curves for lung cancer patients without comorbidity in the Central Denmark Region for four study periods.

in lung cancer treatment might therefore have a smaller impact in the overall prognosis in this group of patients. Further, comorbidity may represent a barrier to treatment in some patients, for instance by contraindication for surgery (eg, severely affected lung function in COPD) or chemotherapy (eg, low World Health Organization performance status in disabling congestive heart failure). As more aggressive treatments become available over time, patients with comorbidity may be offered these treatments less often or tolerate them less well than previously "healthy" patients, and thereby increase the gap in survival between patients with and without comorbidity. Finally, earlier cancer diagnosis in some patients with comorbidities is plausible, because people with comorbidity are subject to closer clinical attention with frequent periodical monitoring and care. ${ }^{10}$ This possible "advantage" in comorbid patients may have been weakened by the generally increased attention to cancer symptoms and more effective work-up introduced by the National Cancer Plan.

Strengths of our study include the population-based design and complete follow-up in a uniform health care system. Still, the accuracy of our estimates depends on the quality of our data. The validity of diagnoses in the DNPR is generally high ${ }^{27,28}$ and, though we are unaware of studies on the specific validity of lung cancer diagnoses in the DNPR,

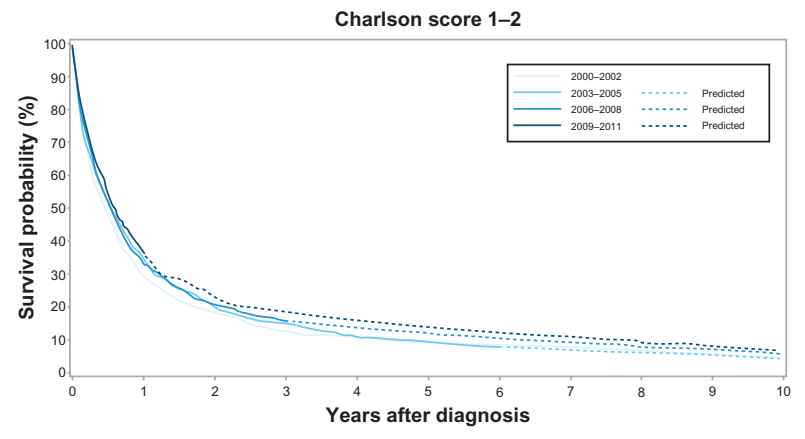

Figure 3 Kaplan-Meier curves for lung cancer patients with medium level of comorbidity in the Central Denmark Region for four study periods.

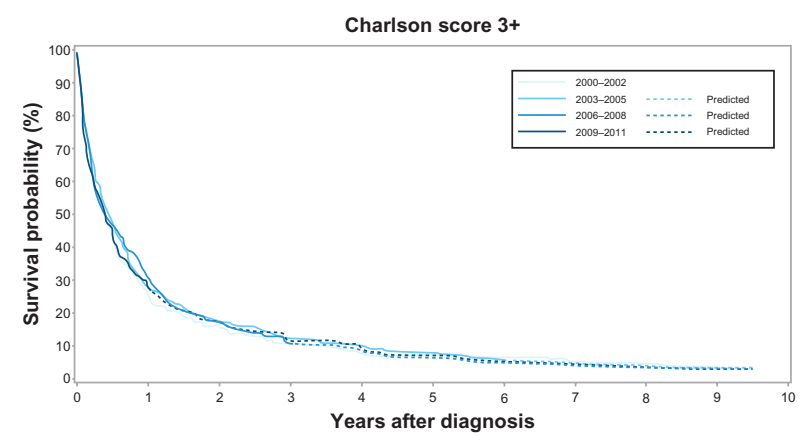

Figure 4 Kaplan-Meier curves for lung cancer patients with high level of comorbidity in the Central Denmark Region for four study periods.

the survival data on colorectal, breast, prostate, bladder, and ovarian cancer are similar, when comparing data from the DNPR with the National Cancer Registry. ${ }^{29,30}$ Additionally, we see no reason to suspect that the validity has changed from 2000 to 2011. Any misclassification of lung cancer patients would most likely be non-differential over time and between different levels of comorbidity; because we expect all lung cancer cases to be hospitalized, and it is unlikely that such bias would produce the time-trends in survival or change in the impact of comorbidity that we found. Finally, we measured comorbidity by the CCI which has a documented high accuracy when used with ICD diagnoses in the DNPR. ${ }^{31}$

Our study also has certain limitations. First, we lacked information on cancer stage at diagnosis, and treatment, which would have enabled us to examine whether improvements in survival were caused by earlier diagnosis and hence more localized disease at diagnosis or by improvements in treatments. On the other hand, our finding of a moderate and perhaps relatively increasing impact of comorbidity on prognosis would be unaffected by this. Second, our use of survival estimates from hybrid analysis might be less correct than observed survival estimates. In our view, this disadvantage is balanced by the possibility of tracking recent improvements in survival; moreover the predictions of the hybrid analysis are based on the survival experience in previous study periods, and are thus conservative estimates. Third, we only studied patients diagnosed in the Central Denmark Region. But, this region consists of mixed rural and urban areas, reflecting Denmark's overall population; likewise the region has both several district hospitals and one large teaching hospital, so that we assume that selection problems are minimal. Fourth, we used data from hospitals to obtain data on comorbidity. Only severe cases of chronic diseases have been treated in hospitals and thereby registered in the DNPR with the disease. Mild or moderate comorbidity (ie, COPD, diabetes) may only have received treatment in general practice and therefore was not included in this study. 


\section{Conclusion}

In conclusion, we found an increasing survival of lung cancer patients diagnosed in the Central Denmark Region from 2000 to 2011, which was most prominent for women, patients under 80 years, and in patients with no or medium level of comorbidity. These findings are in line with extant knowledge on this field. The survival has improved after the introduction of several health initiatives started by the Danish government in the last decade along with the introduction of more aggressive treatments regiments. Despite improvements in survival, the prognosis for lung cancer is still poor with an overall 5 -year survival of about $15 \%$, and comorbidity remains a negative prognostic factor. Finally, our results support a recent initiative launch by the Danish National Board of Health, which focuses on optimizing the treatment of comorbidities among cancer patients.

\section{Disclosure}

The authors have no conflicts of interest to report in this work.

\section{References}

1. Ferlay J, Shin HR, Bray F, Forman D, Mathers C, Parkin DM. Estimates of worldwide burden of cancer in 2008: GLOBOCAN 2008. Int $J$ Cancer. 2010;127(12):2893-2917.

2. Nagai K, Yoshida J, Nishimura M. Postoperative mortality in lung cancer patients. Ann Thorac Cardiovasc Surg. 2007;13(6):373-377.

3. Colinet B, Jacot W, Bertrand D, et al. A new simplified comorbidity score as a prognostic factor in non-small-cell lung cancer patients: description and comparison with the Charlson's index. $\mathrm{Br} J$ Cancer. 2005;93(10):1098-1105.

4. Crino L, Weder W, van Meerbeeck J, Felip E. Early stage and locally advanced (non-metastatic) non-small-cell lung cancer: ESMO Clinical Practice Guidelines for diagnosis, treatment and follow-up. Ann Oncol. 2010;21 Suppl 5:v103-v115.

5. Jørgensen TL, Hallas J, Friis S, Herrstedt J. Comorbidity in elderly cancer patients in relation to overall and cancer-specific mortality. Br J Cancer. 2012;106(7):1353-1360.

6. Deleuran T, Søgaard M, Frøslev T, et al. Completeness of TNM staging of small-cell and non-small-cell lung cancer in the Danish cancer registry, 2004-2009. Clin Epidemio. 2012;(4 Suppl 2):39-44.

7. Young RP, Hopkins RJ, Christmas T, Black PN, Metcalf P, Gamble GD. COPD prevalence is increased in lung cancer, independent of age, sex and smoking history. Eur Respir J. 2009 2009;34(2):380-386.

8. Doll R, Hill AB. The mortality of doctors in relation to their smoking habits: a preliminary report. 1954. BMJ. 2004;328(7455):1529-1533; discussion 1533.

9. Viegi G, Scognamiglio A, Baldacci S, Pistelli F, Carrozzi L. Epidemiology of chronic obstructive pulmonary disease (COPD). Respiration. 2001;68(1):4-19.

10. Janssen-Heijnen ML, Smulders S, Lemmens VE, Smeenk FW, van Geffen HJ, Coebergh JW. Effect of comorbidity on the treatment and prognosis of elderly patients with non-small cell lung cancer. Thorax. 2004;59(7):602-607.

11. Asmis TR, Ding K, Seymour L, et al. Age and comorbidity as independent prognostic factors in the treatment of non small-cell lung cancer: a review of National Cancer Institute of Canada Clinical Trials Group trials. J Clin Oncol. 2008;26(1):54-59.
12. Strand TE, Rostad H, Wentzel-Larsen T, von Plessen C. A populationbased evaluation of the seventh edition of the TNM system for lung cancer. Eur Respir J. 2010;36(2):401-407.

13. Blanco JA, Toste IS, Alvarez RF, Cuadrado GR, Gonzalvez AM, Martin IJ. Age, comorbidity, treatment decision and prognosis in lung cancer. Age Ageing. 2008;37(6):715-718.

14. Tammemagi CM, Neslund-Dudas C, Simoff M, Kvale P. Impact of comorbidity on lung cancer survival. Int J Cancer. 2003;103(6): 792-802.

15. Battafarano RJ, Piccirillo JF, Meyers BF, et al. Impact of comorbidity on survival after surgical resection in patients with stage I non-small cell lung cancer. J Thorac Cardiovasc Surg. 2002;123(2):280-287.

16. Vulto AJ, Lemmens VE, Louwman MW, et al. The influence of age and comorbidity on receiving radiotherapy as part of primary treatment for cancer in South Netherlands, 1995 to 2002. Cancer. 2006;106(12):2734-2742.

17. Grønberg BH, Sundstrøm S, Kaasa S, et al. Influence of comorbidity on survival, toxicity and health-related quality of life in patients with advanced non-small-cell lung cancer receiving platinum-doublet chemotherapy. Eur J Cancer. 2010;46(12):2225-2234.

18. Read WL, Tierney RM, Page NC, et al. Differential prognostic impact of comorbidity. J Clin Oncol. 2004;22(15):3099-3103.

19. Danish Health and Medicines Authority. The National Cancer Plan Summary and Recommendations. Copenhagen: National Board of Health; 2005. Available from: http://www.sst.dk/publ/Publ2005/PLAN/kraeftplan2/KraeftplanII_UK/Kraeftplan_II_UK.pdf. Accessed February 5, 2013.

20. Danish Health and Medicines Authority. National Integrated Cancer Pathways. Copenhagen: National Board of Health; 2009. Available from: http://www.sst.dk/English/Cancer_pathways.aspx. Accessed February $5,2013$.

21. National auditrapport januar 2011 - december 2011 [Danish]. Copenhagen: Dansk Lunge Cancer Register: 2011. Available from: http://www.lungecancer.dk/documents/00224.pdf. Accessed December 4, 2012.

22. Charlson ME, Pompei P, Ales KL, MacKenzie CR. A new method of classifying prognostic comorbidity in longitudinal studies: development and validation. J Chronic Dis. 1987;40(5):373-383.

23. Quan H, Sundararajan V, Halfon P, et al. Coding algorithms for defining comorbidities in ICD-9-CM and ICD-10 administrative data. Med Care. 2005;43(11):1130-1139.

24. Brenner H, Rachet B. Hybrid analysis for up-to-date long-term survival rates in cancer registries with delayed recording of incident cases. Eur J Cancer. 2004;40(16):2494-2501.

25. Ramsey SD, Howlader N, Etzioni RD, Donato B. Chemotherapy use, outcomes, and costs for older persons with advanced non-small-cell lung cancer: evidence from surveillance, epidemiology and end resultsMedicare. J Clin Oncol. 2004;22(24):4971-4978.

26. D’Addario G, Fruh M, Reck M, Baumann P, Klepetko W, Felip E. Metastatic non-small-cell lung cancer: ESMO Clinical Practice Guidelines for diagnosis, treatment and follow-up. Ann Oncol. 2010;(21 Suppl 5): v116-v119.

27. Søgaard M, Kornum JB, Schønheyder HC, Thomsen RW. Positive predictive value of the ICD-10 hospital diagnosis of pleural empyema in the Danish National Registry of Patients. Clin Epidemiol. 2011;3:85-89.

28. Thomsen RW, Lange P, Hellquist B, et al. Validity and underrecording of diagnosis of COPD in the Danish National Patient Registry. Respir Med. 2011;105(7):1063-1068.

29. Kort- og langtidsoverlevelse efter indlæggelse for udvalgte kræftsygdomme i Nordjyllands, Viborg og Århus amter 1985-2003 [Danish]. Department of Clinical Epidemiology, Aarhus University Hospital. Available from: http://kea.au.dk/files/25.pdf. Accessed 2005.

30. Gjerstorff ML. The Danish Cancer Registry. Scand J Public Health. 2011;39(Suppl 7):42-45.

31. Thygesen SK, Christiansen CF, Christensen S, Lash TL, Sørensen HT. The predictive value of ICD-10 diagnostic coding used to assess Charlson comorbidity index conditions in the population-based Danish National Registry of Patients. BMC Med Res Methodol. 2011;11:83. 


\section{Publish your work in this journal}

Clinical Epidemiology is an international, peer-reviewed, open access journal focusing on disease and drug epidemiology, identification of risk factors and screening procedures to develop optimal preventative initiatives and programs. Specific topics include: diagnosis, prognosis, treatment, screening, prevention, risk factor modification, systematic

Submit your manuscript here: http://www.dovepress.com/clinical-epidemiology-journal reviews, risk \& safety of medical interventions, epidemiology \& biostatical methods, evaluation of guidelines, translational medicine, health policies \& economic evaluations. The manuscript management system is completely online and includes a very quick and fair peer-review system, which is all easy to use. 